\title{
Pesquisa do mundo, pesquisa da alma: considerações a respeito da poética de João Guimarães Rosa
}

\begin{abstract}
Resumo: O presente estudo propõe uma reflexão acerca da poética de João Guimarães Rosa (19081967). A hipótese é que a produção do escritor apresenta características essenciais à constituição da lírica moderna. Ao abolir a linha divisória entre poesia e prosa narrativa, Rosa coloca-se na linha de frente daqueles narradores que, ao conceder primazia ao artesanato formal do objeto literário, creditam à palavra o poder de extravasar os grilhões da referencialidade naturalista à qual se rendera grande parte da ficção brasileira produzida até então. Inquieta, obscura, experimental, a escritura de Rosa subverte os dados cristalizados pela tradição e oferece ao leitor uma experiência de estranhamento em relação à própria linguagem, tomada como instrumento privilegiado de investigação de um real fugidio e paradoxal, arisco às investidas da razão objetiva.
\end{abstract}

\begin{abstract}
This essay considers the poetics of João Guimarães Rosa (1908-1967). The hypothesis is that the writer's production shows characteristics that are essential to the nature of the modern lyric. Abolishing the frontier between poetry and narrative prose, Rosa is in the frontline of those writers who grant primacy to the formal aspects of the literary object and concede the word a power to overflow the limits of the naturalist aesthetics, a dominant tendency in the Brazilian literary fiction until then. Restless, obscure, experimental, Rosa's scripture subverts the crystallized tradition and offers the reader an experience of strangeness regarding language itself, taken as a privileged instrument of investigation of a paradoxical and fleeting reality immune to the assaults of objective reason.
\end{abstract}

Keywords: Guimarães Rosa; modern lyric; poetry Poesia.

\section{As fontes da Poesia}

Este breve artigo é uma reflexão sobre a Poesia e sobre um poeta - João Guimarães Rosa. Embora esteja compreendida formalmente dentro dos limites da prosa, a arte do escritor mineiro tem, a nosso ver, suas raízes mais fundas numa necessidade tenaz de indagação a respeito da existência. Sob esse aspecto, a obra de Rosa pode ser tomada como uma longa pesquisa poética, um persistente indagar-se a respeito do movimento do mundo - suas misturas, seus mistérios - e dos movimentos da alma - esse grande, confuso e feroz espaço-

\footnotetext{
* Ygor Raduy é mestrando vinculado ao Programa de Pós-Graduação da Universidade Estadual de Londrina. Na mesma instituição, desenvolve pesquisa sobre João Guimarães Rosa desde 2002.
} 
tempo que humanamente aprendemos a chamar de alma. É imprescindível que alguém esteja atento a tais movimentos. É imprescindível que alguém registre-os na forma de uma poesia vital, com densidade suficiente para traduzir, de alguma forma, essa coisa fugidia que é a vida, essa coisa complicada que é o mundo. Não se sabe até que ponto a poesia traduz o mundo ou até que ponto ela forja um mundo outro. São questões tão antigas, mas é preciso repropô-las sempre. O poeta é aquele que não perde jamais a capacidade de espantar-se com a existência das coisas do mundo? Façamos uma meditação sobre a poesia. O poeta talvez seja aquele que, passado o primeiro espanto, reveste a si mesmo de uma retidão necessária ao exaustivo ofício de dissecar as coisas do mundo.

E como se disseca um mundo? Como separar o mundo em partes, como olhar para cada uma dessas partes separadamente? Rosa, como legítimo partícipe da estirpe dos escritores-pesquisadores, disseca o seu mundo referencial - o Norte bravo de Minas - com a argúcia de um cientista. Em Rosa, a Poesia só se permite nascer depois de uma exaustiva documentação da paisagem física e humana. São muito conhecidas as suas cadernetas e o seu constante hábito de compendiar cada detalhe a respeito daquele ambiente. $\mathrm{O}$ escritorpesquisador só se permite artista depois dessa longa imersão na referencialidade daquilo que escolhe como motivo de sua arte. Em 1952, Rosa volta ao sertão mineiro e imerge novamente naquela paisagem, exercendo papéis simultâneos de biólogo, etnólogo e filólogo interessando em armazenar o máximo de informação possível. Em 1956, vêm à luz Corpo de Baile e Grande sertão: veredas. Apesar de todo o exaustivo trabalho de resgate e documentação científica, a Poesia está no auge. O material bruto recolhido pelo escritor - a dissecação do mundo - agira como potencializadora de seu ofício poético.

A obra de Rosa - assim como já foi apontado repetidamente por grande parte da crítica - possui um teor universal que a descola da realidade do Norte de Minas - onde, por sinal, tem raízes profundas - e a eleva a um patamar de universalidade. Essa realidade fornece uma capa espessa, muito bem tecida, fabricada com toda a rica massa da cultura regional absorvida por Rosa em sua infância e durante suas incursões pelo sertão. Por baixo dessa trança real desdobram-se os infinitos patamares místico-religiosos, históricos, filosóficos - ou seja, um incomensurável repertório de referências cifradas a temas e motivos da cultura do Ocidente e do Oriente. O edifício da obra de Rosa, embora disfarçado de sertanejo, opera em muitos patamares. Ao pesquisador, interessa o modo através do qual a obra de Rosa mescla, de uma forma muito astuciosa, essa realidade primeira com outras diversas realidades provenientes de múltiplos espaços e temporalidades que o escritorpesquisador foi compendiando durante a vida. Assim, a escrita de Rosa caracteriza-se por ser, 
em sua essência, uma escrita misturada, obtida através de mesclas, experimentos, alquimias e daí talvez provenha o seu propalado poder de fascínio.

Aqui, tomamos a obra de Rosa como promotora de um desafio duplo de pesquisa a respeito do existente - a) a tenaz pesquisa do mundo empírico, trabalho do cientista, conjugada à b) delicada pesquisa da alma, trabalho do fino artífice. A partir dessas reflexões, nossa idéia inicial era, aprofundando-nos na discussão a respeito das variadas formas através das quais essa voz poética está plasmada, tentar desentranhar do edifício rosiano uma possível concepção poética que perpassa, de uma ponta a outra, a obra do escritor. Como tal empresa foi revelando-se aos poucos quase impossível, dada a complexidade do material a ser tratado, contentamo-nos em esboçar uma breve meditação a respeito dos significados que a Poesia assume na obra rosiana e as variadas formas pelas quais o escritor agencia o confronto entre o mundo que o interessa e a linguagem que ele forjou para representá-lo. Tal representação, entretanto, não é aquela resultante de um procedimento mimético, naturalista, que se submete às diretrizes do factual e pensa estar reproduzindo o real em sua suposta essencialidade. A representação, em Rosa configura-se através de um pathos da invenção, que re-transfigura e re-inventa o mundo a fim de melhor representá-lo artisticamente.

\section{Poesia em Rosa}

O primeiro passo de um caminho possível para enfrentar o desafio de pensar a persistência de uma voz lírica e de um lirismo essencial na ficção de João Guimarães Rosa talvez seja reportarmo-nos à Grécia Antiga. A peculiaridade mais essencial da Poesia, da forma como tem sido compreendida desde Aristóteles, é a de reorganizar os elementos do real de acordo com um mecanismo artístico que deve pouco ou nada a parâmetros da realidade empírica. No capítulo IX da Poética, o pensador estagirita empreende a célebre distinção entre Poesia e História. Segundo Aristóteles, a Poesia, enunciando verdades gerais, encerra mais filosofia e elevação que a História, que trata apenas de verdades particulares. A matéria-prima do poeta é o amplo espectro do possível; a do historiador, o repertório restrito de fatos reais, acontecidos e documentados (ARISTÓTELES, 1990, p.53). Essa pista antiga, colhida na primeira tentativa de teorização literária que se tem notícia - a Poética - auxilia no sentido de compreender, já na modernidade - ou pós-modernidade, como querem alguns - a obra de arte como elemento transfigurador. O ímpeto do artista, segundo tal noção, trabalha no sentido de transformar, distorcer, reorganizar ou, em última instância, dissolver e aniquilar a realidade 
mundana e, a partir desse caldo distorcido, engendrar um novo sistema, tão ou mais real que o anterior. Hugo Friedrich aponta:

Quando a poesia moderna se refere a conteúdos [...] não os trata descritivamente [...] Ela nos conduz ao âmbito do não-familiar, torna-os estranhos, deforma-os. A poesia não quer mais ser medida em base do que comumente se chama realidade [...] (FRIEDRICH, 1978, p.16).

Essas reflexões conduzem à questão essencial da lírica moderna. A nosso ver, a modernidade trouxe em seu bojo a radicalização do pensamento aristotélico - o poeta moderno (ou, mais amplamente, o artista de índole moderna) rejeita veementemente o caráter mimético e servil da obra de arte em relação ao real e instaura um fazer artístico cuja vinculação com a realidade empírica passa a segundo plano. O que importa, a partir do projeto moderno, é a invenção tomada em seu sentido mais amplo - como experimento formal e construção de mundos possíveis; como rejeição de padrões realistas de composição e intensa elaboração dos recursos expressivos, que aí atuam não como meros indicadores, símbolos transparentes de significantes empíricos, mas passam a valer em si mesmos. No caso do literário, aproximamo-nos da concepção de Sartre da palavra-coisa: a palavra renuncia à sua “função utilitária e simbólica, transparente com vista ao mundo objetivo, em favor da opacidade, do ser símbolo e gozo dela mesma” (SCHWARZ, 1991, p.381).

Indagamos: em que termos poderia a obra do escritor mineiro ser considerada lírica? É possível rastrear, pela obra de Rosa, traços de uma suposta voz lírica enraizada na modernidade? A discussão, inevitavelmente, passa pela questão dos gêneros literários. Existem inúmeros estudos, especialmente sobre Grande sertão: veredas, que buscam aí investigar a presença (ou não) dos gêneros literários da tradição clássica. A maioria dos críticos parece concordar com o fato de que, no romance, estão presentes, dinamicamente integrados, elementos épicos, líricos e dramáticos. Se falamos em épica, avulta o tom grandiloqüente das cenas de batalha, a saga guerreira encampada no seio do sertão bravo ou a efígie valorosa de personagens como Joca Ramiro e Medeiro Vaz. Se falamos em drama, aponta-se a eficiente estrutura narrativa que confronta dramaticamente um velho ex-jagunço a um interlocutor citadino. Quando se fala em lírica, fica evidente a natureza subjetiva da narração em primeira pessoa ou as cenas francamente afetuosas entre Riobaldo e Diadorim. Eduardo Coutinho pondera que a coexistência dos gêneros no romance é relevante na medida em que efetua um questionamento do caráter excludente dos gêneros tradicionais (COUTINHO, 1993). Coutinho diz mais:

O que nos interessa realmente é explicitar um paradoxo que confere ao texto rosiano grande dinamismo e elasticidade. Pois se tais elementos se acham indiscutivelmente presentes, coexistindo com certa harmonia, por outro lado eles são parodiados, de modo às vezes 
contundente, dando margem à observação que ora fazemos de que o livro é uma "síntese crítica" de todas essas formas tradicionais (COUTINHO, 1993, p.72).

Entretanto, acreditamos, com Roberto Schwarz, que o lirismo em Rosa, antes de presentificar-se na intimidade da estrutura do narrado, constitui "uma atitude em face da linguagem e da realidade, da relação entre as duas, que uma concepção de arquitetura narrativa" (SCHWARZ, 1991, p.379). Nossa hipótese é que o conteúdo lírico da escritura rosiana só é plenamente observável quando se considera a posição peculiar do escritor frente ao seu instrumento de trabalho e o modo intrincado como linguagem e realidade se combinam na construção da obra. Lembremos aqui que Guimarães Rosa é um escritor preocupado em forjar uma linguagem vital, desautomatizada, livre das amarras da gramática formal. Assim como a melhor poesia, a literatura de Rosa é um esforço perene de desautomatização e subversão dos paradigmas cristalizados pela tradição. A respeito, vejamos um trecho da correspondência de Rosa com seu tradutor alemão, em que o autor se refere às dúvidas que apareciam ao longo da tradução:

Observo, também, que quase sempre as dúvidas decorrem do "vício" sintático, da servidão à sintaxe vulgar e rígida, doença de que todos sofremos. Duas coisas convém ter sempre presente: tudo vai para a poesia, o lugar-comum deve ter proibida a entrada, estamos é descobrindo novos territórios de sentir, do pensar, e da expressividade; as palavras valem "sozinhas". Cada uma por si, com sua carga própria, independentes, e às combinações delas permitem-se todas as variantes e variedades (ROSA, 2003, p.314).

Tal como se observa em termos de lírica moderna, a linguagem de Rosa se constrói sempre em oposição ao normativo - daí ser possível percebê-la através de categorias negativas tais como des-orientação, dis-solução, fragmentação, des-locamento, dis-sonância e obscuridade. Em oposição à objetividade documental, que toma como base as manifestações de uma realidade rasteira - fenômeno freqüente em nossa tradição literária (vide a longa tradição naturalista em nossas letras) - a literatura de Rosa, ao mesmo tempo em que funda suas raízes nas peculiaridades de um ethos muito particular - o sertão de Minas - insinua-se em direção à dissolução de parâmetros realistas de composição. A voz lírica aí presente atua como desconstrutora dos esquemas tradicionais de representação literária e instaura uma estética anti-normativa, muito próxima à poesia e ao mito, cuja especificidade reside no perene esforço de invenção, via palavra poética, de um universo dotado de leis próprias. A descritividade naturalista é substituída por uma estética do estranho e do obscuro. A respeito disso, vejamos mais um trecho da correspondência de Rosa com seu tradutor alemão:

Naturalmente, em Corpo de Baile, há trechos e passagens "obscuros". Mas o Corpo de Baile tem que ter passagens obscuras! Isso é indispensável. A excessiva iluminação, geral, só no nível do raso, da vulgaridade. Todos os meus livros são simples tentativas de rodear e devassar um pouquinho o mistério cósmico, esta coisa movente, impossível, perturbante, rebelde a qualquer lógica, que é a chamada "realidade", que é a gente mesmo, o mundo, a vida. Antes o 
obscuro que o óbvio, que o frouxo. Toda lógica contém inevitável dose de mistificação. Toda mistificação contém boa dose da inevitável verdade. Precisamos também do obscuro (ROSA, 2003, p.238).

A obscuridade pretendida pelo escritor é também um dos pressupostos básicos da concepção moderna de lírica. Ao abdicar de uma representação calcada em princípios realistas, ao preterir a objetividade em favor dessa lógica do estranho, o artista engendra um objeto estético anormal, que exige do leitor uma atitude igualmente anti-objetiva. Não é por acaso que muitos leitores, ao se depararem, pela primeira vez, com um texto de Rosa, qualificam-no de hermético ou de incompreensível. Parte dessa impressão tende a se diluir com a progressão da leitura. Porém, é exatamente na confluência dissonante entre incompreensibilidade e fascinação que reside um dos pilares da lírica moderna. Mesmo sem apreender intelectualmente o conteúdo de certas passagens, mesmo sem entendê-las objetivamente, o leitor de Guimarães Rosa é capaz de, através de certas sugestões fônicas e semânticas que o texto apresenta, apreendê-lo - absorvê-lo - de forma não-racional. O papel da intuição é fundamental. A Poesia e seu enigma residem justamente aí - no conteúdo que nunca é desvelado por completo mas que, por via subterrânea, produz no âmago do leitor um estranhamento essencial. A experiência de estranhamento através da linguagem, da forma como é compreendida na modernidade, especialmente com Nietzsche, corresponde a uma perturbação das categorias tradicionais de pensamento. Levada ao limite, tal experiência permite uma revisão crítica, de índole filosófica, de certos paradigmas sob os quais se assenta uma cultura.

Aqui, recorremos a uma pequena pausa explicativa. Afinal, a seguinte questão pode ser colocada: como é possível, através de uma experiência de linguagem, repensar as cristalizações da cultura? Se pensarmos com Nietzsche e aceitarmos a tese segundo a qual o desenvolvimento da linguagem é paralelo ao desenvolvimento da consciência e ambos decorrem da necessidade de estabelecer coordenadas que possibilitem o convívio gregário, teremos também que a linguagem cotidiana - indispensável à convivência gregária - está enraizada na tendência de simplificar, tornar comum, tornar reconhecível tudo aquilo que é complexo e singular. Diz Nietzsche:

Não basta utilizar as mesmas palavras para compreendermos uns aos outros; é preciso utilizar as mesmas palavras para a mesma espécie de vivências interiores, é preciso, enfim, ter a experiência em comum com o outro. [...] entre todas as forças que até agora dispuseram do ser humano a mais poderosa deve ter sido a fácil comunicabilidade da necessidade, que é, em última instância, o experimentar vivências apenas medianas e vulgares. (NIETZSCHE, 1992, p.182) 
Para o filósofo alemão, é somente a reconfiguração da linguagem, entendida como base de todo a simplificação do vir-a-ser exigida pelo pensamento consciente, que possibilita a revisão dos paradigmas da cultura. Não é à toa que Nietzsche já foi caracterizado como filósofo-artista: o seu pensamento surge inextricavelmente ligado à linguagem pela qual é expresso, ou seja, a experiência de pensamento é também uma experiência de linguagem. Assim também em Rosa, a nosso ver um artista-pensador, para o qual somente uma linguagem transfigurada pode almejar a transfiguração de um mundo. A linguagem, entendida como substrato do esquematismo conceitual, é um campo de ação privilegiado a um artista que, como Rosa, rejeita o automatismo cego da língua cotidiana e parte em busca do experimento. É nesse sentido que uma experiência de linguagem pode ser interpretada como uma crítica da cultura e, mais ainda, como abertura, possibilitada pela poesia, a novos campos do pensar, do conhecer e, sobretudo, do viver.

\section{Um lirismo à parte}

Nesse ponto de nossa reflexão, o lirismo, entendido como instância que possibilita a experiência do estranhamento, deixa de ser mera representação subjetiva de uma determinada realidade para assumir um papel determinante. Sob esse viés, toda a obra de Rosa pode ser considerada modernamente lírica, na medida em que opera, a todo instante, indagações essenciais a respeito da existência, apondo a cada uma delas respostas paradoxais ou contraditórias que desorientam e inquietam, e que jamais fornecem soluções apaziguadoras. A Poesia nasce, a nosso ver, dessa inquietude, desse frêmito, dessa lacuna, dessa falta de resolução, de escolha entre uma coisa e outra. A Poesia reside no paradoxo. Ouçamos Octavio Paz, poeta:

Há, enfim, imagens que realizam o que parece ser uma impossibilidade tanto lógica quanto lingüística: casamento dos contrários. Em todas elas - apenas perceptível ou inteiramente realizado - observa-se o mesmo processo: a pluralidade do real manifesta-se como unidade última, sem que cada elemento perca sua singularidade especial. As plumas são pedras, sem deixarem de ser plumas. A linguagem, voltada sobre si mesma, diz o que por natureza parecia lhe escapar. O dizer poético diz o indizível (PAZ, 1982, p.136).

A observação do poeta mexicano é de grande valia para compreender o lirismo que perpassa a produção moderna, aí incluída a de Guimarães Rosa. Ao invés de optar por uma lógica exclusiva - as coisas são ou não são - , o artista lida com um universo onde opostos coexistem em paradoxal comunhão - as coisas são e não são. O texto rosiano, assim, resulta da sobreposição mesclada de uma gama de discursos díspares e aparentemente contraditórios. Com efeito, como reitera a todo instante o narrador de Grande sertão: veredas, tudo é e não é, 
o diabo existe e não existe (ROSA, 2003). Recorde-se aí que todo o romance é baseado na ânsia e na tentativa do ex-jagunço de esclarecer o sentido de sua experiência. Do interlocutor urbano a quem se dirige, Riobaldo espera respostas, certezas, confirmações. Todo o seu discurso é movido por um desejo de esclarecimento que, contudo, nunca se consuma. Veja-se:

Que isso foi o que sempre me invocou, o senhor sabe: eu careço de que o bom seja bom e o rúim ruím, que dum lado esteja o preto e do outro o branco, que o feio fique bem apartado do bonito e a alegria longe da tristeza! Quero os todos pastos demarcados... Como é que eu posso com esse mundo? A vida é ingrata no macio de si; mas transtraz a esperança mesmo do meio do fel do desespero. Ao que, este mundo é muito misturado... (ROSA, 2003, p.237).

Lirismo sui generis, que agencia o confronto entre desejo de esclarecimento e sua impossibilidade. Ao fim do narrado, Riobaldo constata, a despeito de toda a sua vontade de verdade, que não há Razão capaz de esclarecer o movimento misturado de sua existência e todo o significado desta, mesmo que fugidio, reside nesse mesmo complicado movimento - a travessia - última palavra do romance e palavra-símbolo da poética de Rosa. Um lirismo trágico, diríamos, na medida em que apresenta a condição humana em toda a sua feroz inexorabilidade; a existência como entidade impermeável ao conhecimento de ordem racional. Nesse jogo difícil entre a vontade de conhecer e a inapreensiblidade da coisa a ser conhecida - no caso, a própria existência - a única saída possível parece ser aquela posta em prática pela invenção poética, parceira da magia, dotada da capacidade de alterar, ampliar e subverter a estrutura daquilo a que confusamente chamamos real.

\section{Referências}

ARISTÓTELES . A Poética Clássica: Aristóteles, Horácio e Longino. Introdução de Roberto de Oliveira Brandão. Tradução do grego e do latim por Jaime Bruna. São Paulo, Cultrix: 1990.

COUTINHO, Eduardo. Em busca da terceira margem: ensaios sobre Grande sertão: veredas. Salvador: Fundação Casa de Jorge Amado, 1993.

SCHWARZ, Roberto. Grande sertão: estudos. In: COUTINHO, Eduardo F. (Org.) Guimarães Rosa. Rio de Janeiro/ Brasília: Civilização Brasileira/INL, 1991. p. 378-389. v. 6. (Coleção Fortuna Crítica)

FRIEDRICH, Hugo. Estrutura da Lírica Moderna. São Paulo: Duas Cidades, 1978.

NIETZSCHE, Friedrich. Além do Bem e do Mal: prelúdio a uma filosofia do futuro. Tradução, notas e posfácio Paulo César de Souza. São Paulo: Companhia das Letras, 1992.

PAZ, Octavio. O Arco e a Lira. Tradução de Olga Savary. Rio de Janeiro: Nova Fronteira, 1982. 
ROSA, João Guimarães. Grande sertão: veredas. Rio de Janeiro: Nova Fronteira, 2003.

. João Guimarães Rosa: correspondência com seu tradutor alemão Curt MeyerClason. Rio de Janeiro: Nova Fronteira: Academia Brasileira de Letras; Belo Horizonte: Ed. da UFMG, 2003. 